\title{
The Role of Community to Encourage Micro, Small, and Medium Enterprises in Marketing Digital Adoption Behavior
}

\author{
Adellina Sendy Widyaswara, Suci Paramitasari Syahlani*, Fransiskus Trisakti \\ Haryadi \\ Departement of Livestock Socio-Economics, Faculty of Animal Science Universitas Gadjah Mada, Jl. Fauna No.03, \\ Bulaksumur, Yogyakarta 55281 \\ *Corresponding author.Email: suci.syahlani@ugm.ac.id
}

\begin{abstract}
Covid-19 had a major impact on Micro, Small and Medium Enterprises (MSMEs). SONJO community is a humanitarian organization that focuses on efforts to help MSMEs affected by Covid-19, by encouraging MSMEs to carry out marketing activities through social media. This study aims to analyze the acceptance of digital marketing technology through social media on MSMEs who were members of the community, by comparing the adoption process for MSMEs that were not members of the community. The study was conducted using a survey design and respondents were determined by using a purposive sampling method. Data was collected using a close ended questionnaire. The number of respondents were 145 MSMEs, 74 members of SONJO and 71 non-community members. Data was analysed using Partial Least Square. The results showed that perception ease of use (PEU) affected perception of usefulness (PU) with $\beta=0.47(\mathrm{p} \leq 0.001)$ and then PEU and PU affected attitudes towards social media (ATSM) respectively with $\beta=0.7(p \leq 0.05)$ and $\beta=0.34(p \leq 0.001)$ in MSMEs community members. ATSM and popularity of social media (PSM) affected intention to use social media (IUSM) with a value of $\beta=0.72(\mathrm{p} \leq 0.001)$ and $\beta=0.22(\mathrm{p} \leq 0.05)$, however, trust in social media (TSM) was not significantly affect IUSM $\beta=-0.01(\mathrm{p} \geq 0.05)$. IUSM affected adoption behavior with $\beta=0.9(\mathrm{p} \leq 0.05)$. Different results for MSMEs who were not community members indicating that PEU affected PU with $\beta=0.73(\mathrm{p} \leq 0.05)$. PU influenced ATSM with $\beta=0.9(\mathrm{p} \leq 0.05)$, while effect of PU on ATSM was not significant, with a value of $\beta=0.05(p \geq 0.05)$. Furthermore, ATSM, PSM and TSM affected IUSM by $\beta=0.48(p \leq 0.001) ; \beta=0.48(p \leq 0.01)$; and $\beta=0.21(p \leq 0.05)$. IUSM affected behavior of $\beta=0.90(p \leq 0.01)$. It can be concluded that education carried out by the community was able to accelerate MSMEs SONJO community to adopt social media technology, although trust did not affect attitudes towards social media in marketing activities.
\end{abstract}

Keywords: Community, Covid-19, MSMEs, social media, Sonjo community

\section{INTRODUCTION}

Existence of micro, small, and medium enterprises (MSMEs) face a huge challenge as an impact of dramatic change of external environment caused by CoronaVirus 2019 pandemic or known as Covid-19 [1]. Most businessmen suffer a business activity derivation, financial loss, or even worse, a bankruptcy, during Covid-19 pandemic. Along with the pandemic, online business which relies its business activity in social media, is an example of a business model which successfully survives during pandemic.
Concerning the difficult situation during the pandemic, SONJO (Sambatan Jogja) as one of humanitarian organizations in Yogyakarta, strives to support the micro, small, and medium enterprises which are susceptible to pandemic situations. SONJO uses Whatsapp Group as the main platform to coordinate various programs [2]. Community is important in business as it develops the relationship among members, adds relatives among producers, and a place of knowledge sharing [3]. Previous study finds that joining a community is crucial for business sustainability, because members of a community gain a lot of experience and knowledge, compared to the one who 
does not join any. Therefore, social media takes an important part in defining different perspectives and behavior towards technology acceptance.

Technology Acceptance Model (TAM) is developed to analyze and understand factors influencing the acceptance of technology. Different research contexts require variable intervention to improve the model to describe technology adoption behavior [4]. Several relevant variables which being considered as a context on individual level of social media adoption technology, such as social parameter of external person presence [5], popularity of media [4], and user trust towards social media [6]. Popularity of media is taken into account, however, Bhagat et al., [7] suggests more people using social media that would encourage other people to adopt social media. Nevertheless, trust is a key as adoption requires such a mechanism to satisfy the user. As a result, information which is uploaded on a platform is not being abused or used without the consent of the user [6].

Aim of the study is to review TAM models affected by trust and social media popularity variables in explaining social media usage behavior of MSMEs and analyze the role of community in the social media technology acceptance. The advantage of conducting this study is understanding the social media adoption factor in the business market during Covid-19 pandemic that is expected to solve problems regarding an appropriate survival strategy for MSMEs.

\section{MATERIAL AND METHOD}

\subsection{Material}

This study was conducted involving 145 respondents from existing MSMEs in Yogyakarta. Respondents consisted of 2 two groups: 74 respondents of community members and 71 respondents non-community members. Judgmental sampling methods were for respondent sampling. Instrument used in this study was a questionnaire. Questionnaires contain questions about communication behavior and research variables.

\subsection{Method}

Study was conducted using a survey design. Data was collected by face-to-face interview and by Google Form questionnaire distributed to MSMEs members. Questionnaire test was performed to 60 respondents before it was used for the main data sampling. Validity and reliability were analyzed afterwards. Main data were analyzed using Partial Least Square (PLS) to test the quality of data, including validity and reliability.

Validity tests showed that Average Extracted (AVE) on PEU, PU, ATSM, PSM, TSM, IUSM, and adoption behavior were $0.74 ; 0.73 ; 0.77 ; 0,72 ; 0.74 ; 0.83 ; 0.75$, respectively. Reliability test showed that Cronbach Alpha scores were $0.89 ; 0.9 ; 0.87 ; 0.9 ; 0.88 ; 0.93 ; 0.89$, respectively. Validity tests showed that all variables had AVE scores above 0.5, which proved that all indicators were valid in this study. Reliability test showed that all variables had Cronbach Alpha value above 0.6. Score explained that all variables were reliable. Subsequently, hypothesis tests and descriptive analysis were performed to obtain respondent profiles and communication behavior.

\section{RESULTS AND DISCUSSION}

\subsection{Respondent Characteristics}

The majority $(75.7 \%)$ of respondents were women between 31-40 years old, while non-community members consisted of $60.6 \%$ men between $19-30$ years old. More than half of total respondents had a last education level of diploma and undergraduate. The majority of MSMEs from those two groups had ground assets, excluding building, less than 50 million, and total financial turnover less than 300 million per year. As a result, it is included as micro enterprises.

About $43.2 \%$ of community members used social media less than a year, while $53.5 \%$ non-community members used social media in the last 1-4 years. Those two respondent groups used social media around 1-5 hours a day for business communication, whilst product promotion took less than 4 hours. Business communication mostly used WhatsApp, whereas Instagram was mostly used for product promotion.

Table 1. Hypothesis testing forwards community members

\begin{tabular}{|l|l|l|l|l|l|}
\hline Hypothesis & $\begin{array}{l}\text { Original } \\
\text { Sample }\end{array}$ & Sample Mean & $\begin{array}{l}\text { Standart } \\
\text { Daviation }\end{array}$ & t-statistic & p value \\
\hline PEU $\rightarrow$ PU & 0.700 & 0.74 & 0.058 & 12.133 & $0.000^{\star}$ \\
\hline PEU $\rightarrow$ ATSM & 0.334 & 0.333 & 0.121 & 2.772 & $0.006^{\star}$ \\
\hline PU $\rightarrow$ ATSM & $0 / 468$ & 0.471 & 0.107 & 4.355 & $0.000^{\star}$ \\
\hline ATSM $\rightarrow$ IUSM & 0.724 & 0.720 & 0.109 & 5.548 & $0.000^{\star}$ \\
\hline
\end{tabular}




\begin{tabular}{|l|l|l|l|l|l|}
\hline PSM $\rightarrow$ IUSM & 0.219 & 0.230 & 0.109 & 2.010 & $0.045^{\star}$ \\
\hline TSM $\rightarrow$ IUSM & -0.010 & -0.010 & 0.094 & 0.104 & 0.917 \\
\hline IUSM $\rightarrow$ Adoption behavior & 0.904 & 0.910 & 0018 & 49.069 & $0.000^{\star}$ \\
\hline
\end{tabular}

Table 2. Hypothesis testing towards non-community members

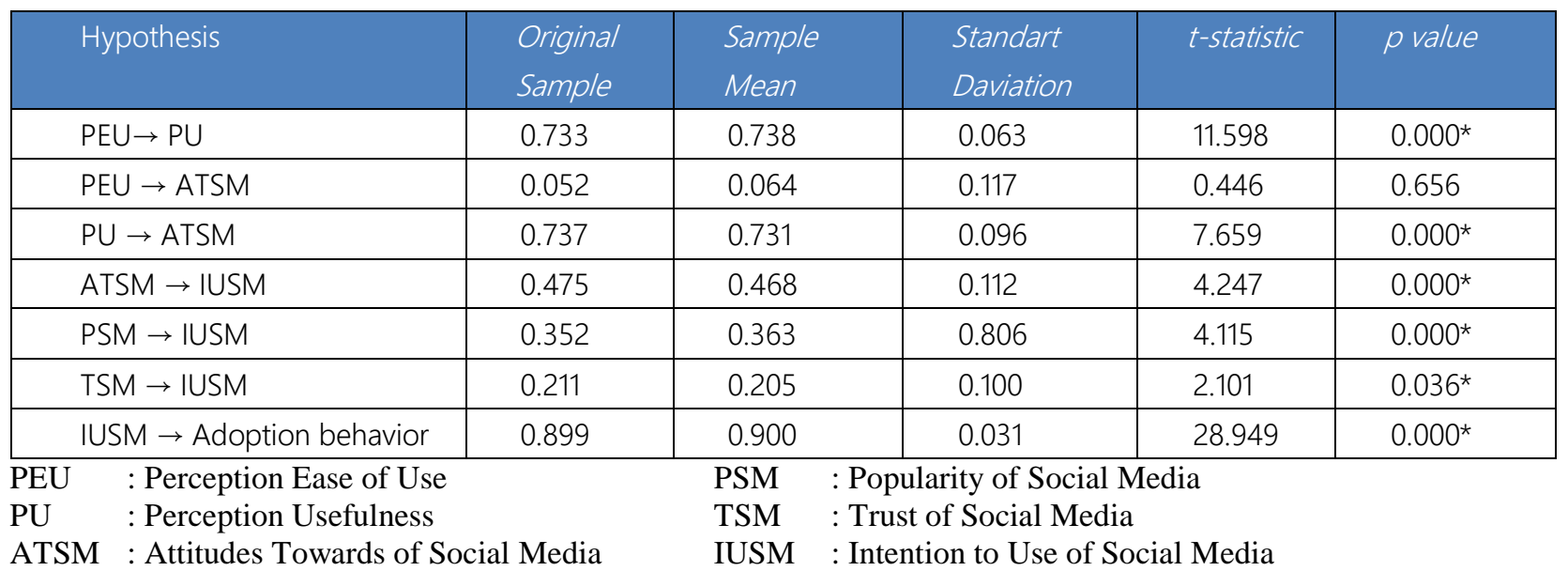

\subsection{Structural Model}

Table 1 showed a hypothesis towards community members respondents that social media perception easy of use affected perception of usefulness and together, perception easy of use and perception of usefulness affected attitudes towards social media. Attitudes and popularity of social media affected intention to use of social media, however trust in social media was not significantly affecting intention to use social media. Intention to use social media affected adoption behavior.

Non-member MSMes groups showed different results, which explained that perception easy of use affected perception of usefulness. Perception of usefulness affected attitudes towards social media. On the other hand, the effect of perception easy of use towards attitudes was not significant. Furthermore, attitudes towards social media, popularity of social media, and trust towards social media altogether affected the intention to use of social media. Intention to use of social media affected behavior of social media usage.

Perception of usefulness of social media in community member groups (Table 1) was affected by perception easy of use of social media for business. Perception easy of use was obtained from education conducted by the community about features utilization and social media platforms. Several online seminars were conducted by the SONJO community, i.e. product promotion methods and reaching the market via social media. Interaction between users and easy-to-use technology form a high knowledge aspect, in addition form a positive attitude towards technology itself $[8,9,10]$.

Interestingly, non-community members respondent group (Table 2) showed that the variable of perception easy of use was not significantly affected attitudes variable., which explained that $53 \%$ of non-community members used social media in the last 1-4 years. Experience in using social media was different compared to members of community groups because $43.2 \%$ of community members used social media for less than one year. Usage length affected perception easy of use, that non-community members were not relevant, possibly related to business activity demand.

Role of the trust variable showed different results in the community members group. Variable of trust towards social media was not significantly affecting the intention to use social media, whilst in non community member group was positively affecting. MSMes trust towards security of social media was not relevant by the reason of community mentor support to use social media, encouraging adoption behavior form.

\section{CONCLUSION}

It can be concluded that trust towards social media technology could not affect the attitude of MSMEs in adopting social media, however, education activities conducted by the community could accelerate MSMEs to adopt social media technology, as a business tool during Covid-19 pandemic. 


\section{REFERENCES}

[1] Taufik and E.A. Ayuningtyas. 2020. Dampak Pandemi Covid-19 terhadap Bisnis dan Eksistensi Platform Online. Jurnal Pengembangan Wiraswasta. 22 (1) : 21-32.

[2] Anonim. 2020. SONJO : Sambatan Jogja. Dapat diakses di : https://sonjo.id/mengenal-sonjo/ (Diakses tanggal15 Desember 2020)

[3] Mclaran, P., and M. Catterall. 2002. Researching the Social Web: Marketing Information from Virtual Communities. Marketing Intelligence and Planning. 20(6): 319-326.

[4] Ruaniar. R., G. Rawski., J. Yang., and B. Johnson. 2013. Technology acceptance model and social media usage: an empirical study on facebook. 27 (1): 7-29.

[5] Legris, P., J. Ingham., and P. Collerette. 2003. Why do people use information technology? Critical review of technology acceptance models. Information and Management. 40(3) : 191-204.

[6] Gefen, D., M. Warkentin., P. Pavlou., and G. Rose. 2002. Egovernment adoption. Proceedings of AMCIS.

[7] Bhagat, P. S., A. Klein. and V. Sharma. 2009. The Impact of New Media on InternetBased Group Consumer Behavior. J. Acad. Bus. Eco.Vol: 9. Pp : 83-94.

[8] Anshori, M.I.S Ubud., Armanu. 2013. Application of Technology Acceptance Model to Wi-Fi User at Economics and Business Faculty of Brawijaya University (Study on Stratum-1 Students). Eur. J. Bus. Manag. 5(17): 57-65.

[9] Davis, F. D. 1989. Perceived Usefulness, Perceived Ease of Use and User Acceptance of Information Technology. MIS Quarterly.

[10] McKechnie, S., H. Winklhofer., C. Enne. 2006. Appliying The Technology Acceptance Model to The Online Retailing of Financial Services. Inter. J. RTL. Dist. Manag. 34(4): 388-410. 